\title{
Polymeric Nanogels as Drug Delivery Systems
}

\author{
J. KOUSALOVÁ ${ }^{1}$, T. ETRYCH ${ }^{1}$ \\ ${ }^{1}$ Institute of Macromolecular Chemistry of the Czech Academy of Sciences, Prague, Czech \\ Republic
}

Received June 1, 2018

Accepted June 28, 2018

\section{Summary}

The present review focuses on the description of the design, synthesis and physico-chemical and biological evaluation of polymer nanogels. Nanogels are robust swollen cross-linked polymer nanoparticles that can be used as highly efficient and biodegradable carriers for the transport of drugs in controlled drug delivery. In this article, various types of nanogels are described and methods for their preparation discussed. The possibility of using synthesized nanosystems for targeting are reviewed to show the potential of tailored structures to reach either solid tumor tissue or direct tumor cells. Finally, the methods for encapsulation or attachment of biologically active molecules, e.g. drugs, proteins, are described and compared.

\section{Key words}

Nanogels • Polymers • Biocompatibility • Degradation • Drug delivery $\bullet$ Drug release

\section{Corresponding author}

T. Etrych, Department of Biomedicinal Polymers, Institute of Macromolecular Chemistry of the Czech Academy of Sciences, Heyrovského nám. 2, 16206 Prague 6, Czech Republic. E-mail: etrych@imc.cas.cz

\section{Introduction}

By definition, nanogels are three-dimensional networks formed by cross-linked polymer chains. Since they are made up of hydrogel particles of nanometers in size, hydrogel and nanoparticle properties occur simultaneously in nanogels. They can be successfully prepared from polymeric precursors or prepared by heterogeneous polymerization of monomers. A key step in the preparation of nanogels is physical or chemical cross-linking (Bae et al. 2005, Oh et al. 2007, Hamidi et al. 2008).

Moreover, nanogel-based nanomedicines should fulfill all the requirements for drug delivery systems. To ensure maximum therapeutic effect with minimal side effects, stable covalent bonds or, less preferably, encapsulation of the active substance must be guaranteed. Indeed, premature release during circulation and in healthy tissues should be reduced and subsequent release at the desired site ensured. An additional important requirement is the possibility of both passive and active targeting to the place of the action. Passive targeting is very important in the targeted treatment of localized vascularized solid tumors or localized points of inflammation. Naturally, it is important for nanogel-based drug delivery systems to be completely non-toxic, non-immunogenic and biocompatible and to be biodegradable to non-toxic degradation products that can be eliminated from the body (Chacko et al. 2012).

\section{Properties of nanogels}

Nanogels are nanoparticles with a particle size of 100-200 nm composed of a hydrogel nanoparticles (Fig. 1) with a particle formed by cross-linking a hydrophilic polymer (Garg et al. 2012). The small size of nanogels enables their rapid response to environmental changes, such as change in $\mathrm{pH}$ or temperature (Soni and Yadav 2016). They can be formed by physically or chemically cross-linked synthetic polymers (Bencherif et al. 2009) or biopolymers (Kabanov and Vinogradov 2009). Due to their large inner surface area, nanogels have a very 
high loading capacity for carried active molecules (Soni and Yadav 2016). This enables the active transport of drugs with significantly prolonged circulation time and increase in the stability in the biological environment (Bae et al. 2008, Soni and Yadav 2016). Generally, nanogels are used to transport biologically active molecules, low- or high-molecular weight active molecules or biomacromolecules (Lee et al. 2007, Bae et al. 2008). In particular, the controlled delivery and release of a wide variety of low-molecular weight drugs has been discussed in the literature (Sharma et al. 2016). Nanogels occur in the form of a three-dimensional structure in which drugs, bioactive copolymers and dispersed liquid phases can be captured (Vintiloiu and Leroux 2008). Furthermore, polymeric nanogels can be chemically modified to contain various ligands for actively targeted drug delivery with possible drug release options (Vinogradov et al. 2005). Interestingly, minimally cross-linked polyelectrolyte nanogels may incorporate biomacromolecules with the opposite charge (Kabanov and Vinogradov 2009).

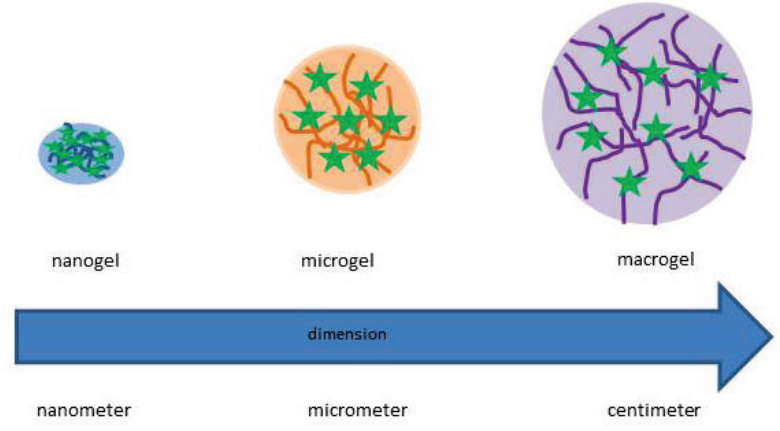

Fig. 1. Schematic representation of polymeric gels of various dimensions.

Generally, nanogels have the following advantages from the biomedical application point of view (Hayashi et al. 2004, Hamidi et al. 2008, Shidhaye et al. 2008, Kabanov and Vinogradov 2009, Uthaman et al. 2014, Sivaram et al. 2015, Sharma et al. 2016):

- Biocompatibility and biodegradability under physiological conditions, without causing an immune response

- Stability and dispersibility in aqueous solutions

- Enhanced bloodstream transport and tissue permeation properties due to their optimal $\mathrm{nm}$ scale size

- Response to a wide range of external stimuli (ionic strength, $\mathrm{pH}$, temperature)

- Characteristics suitable for controlled delivery of hydrophilic and hydrophobic drugs

- Integration of active nanoparticles (NPs), e.g. magnetic NPs, in the range of few nm within their network

- The density of the cross-linking can regulate drug release and also greatly affect the size of the prepared nanogels

- High capacity for absorbing large amounts of water or biological fluids

- Versatile construction with flexible size and large surface

- The controlled release of a wide range of drugs

- The ability to protect their cargos against degradation in vivo

- Prolonged circulation time of carried drugs

- The availability of various polymer materials suitable for nanogel formation and thus the change of nanogel property.

The general classification of nanogels is based on their structure motifs. Individual types of nanogels and their examples are listed in Table 1.

\section{Synthesis of nanogels}

Universally, nanogels can be synthesized using four different procedures, schematically depicted on Figure 2 and listed below.

\section{Physical self-assembling of interacting polymer chains}

Physical interactions between polymers can be divided into electrostatic interactions, Van der Waals interactions, hydrogen bonds and hydrophobic interactions (Zamurovic et al. 2007). Physical self-assembly in the case of nanogel formation usually involves controlled aggregation of amphiphilic or hydrophilic polymers capable of interacting via hydrophobic or electrostatic interactions and/or hydrogen bonds. Usually, the preparation of these nanogels is carried out under mild conditions in an aqueous medium. The size of nanogels is controlled by appropriate selection of polymer concentration, amphiphilic character, functional groups, $\mathrm{pH}$, ionic strength and temperature.

For example, polysaccharide-based nanogels can be prepared by this way. Polysaccharides are used as hydrophilic polymers which are modified by hydrophobic groups. In the case of such modified polymers, the hydrophobic moieties interact with each other and thus the formation of nanoparticles suitable for the transport of active substances is significantly 
increased (Oh et al. 2009).

Another example of hydrophobic interactionbased nanogel formation are systems based on cholesterolmodified pullulans. These systems can be used for transporting various bioactive molecules, for example insulin (Akiyoshi et al. 1998). Hydrophobic interaction can occur even between two types of polymers. For example, lauryl-modified dextrans with $\beta$-cyclodextrins containing polymers were used for successful nanogel formation (Daoud-Mahammed et al. 2007).
The non-covalent interactions between the polymer chains are relatively weaker interactions when compared to covalent bonds. Therefore, stable nanogels of manageable size may be less easily prepared using this approach. On the other hand, physically cross-linked nanogels have a number of advantages over chemically cross-linked nanogels, as no cross-linker and/or catalyst, which may be toxic, is required. However, their lower stability in biological media often does not enable their use in biomedical applications (Uthaman et al. 2014).

Table 1. Nanogel structure classification.

\begin{tabular}{|c|c|c|}
\hline Type of nanogel & Network structure & Example \\
\hline \multirow[t]{2}{*}{ Simple nanogel } & $\begin{array}{l}\text { Cross-linked by self- } \\
\text { aggregation }\end{array}$ & $\begin{array}{l}\text { Cholesterol-bearing pullulan nanogel (Inomoto et al. } \\
\text { 2009, Fujioka-Kobayashi et al. 2012, Morimoto et al. } \\
\text { 2013, Bal et al. 2018) or cholesterol-bearing } \\
\text { enzymatically synthetized amphiphilic glycogen } \\
\text { (Takahashi et al. 2011) }\end{array}$ \\
\hline & $\begin{array}{l}\mathrm{pH} \text { and temperature } \\
\text { responsive semi- } \\
\text { interpenetrating polymer } \\
\text { network }\end{array}$ & $\begin{array}{l}\text { Hydroxypropylcellulose-poly(acrylic acid) (HPC-PAA) } \\
\text { with hydroxyl group of HPC modified by CdSe (Wu et } \\
\text { al. 2010, Nan et al. 2014) }\end{array}$ \\
\hline Hollow nanogel & $\begin{array}{l}\text { Interpenetrating polymer } \\
\text { network }\end{array}$ & $\begin{array}{l}\text { Poly(acrylicacid) (PAA) network and poly(N- } \\
\text { isopropylacrylamid) (PNIPAM) network (PNIPAM/PAA } \\
\text { IPN hollow nanogels) (Xing et al. 2011) }\end{array}$ \\
\hline Core-shell nanogels & $\begin{array}{l}\text { Magnetic particles } \\
\text { encapsulated by the } \\
\text { synthetized polymer gel }\end{array}$ & $\begin{array}{c}\text { Poly(acrylamide) or poly(acrylamide-vinyl amine) } \\
\text { (shell) with magnetic core }\left(\mathrm{Fe}_{3} \mathrm{O}_{4} \text { nanoparticles) (Sun et }\right. \\
\text { al. } 2006, \mathrm{Li} \text { et al. } 2017)\end{array}$ \\
\hline Hairy nanogel & $\begin{array}{l}\text { Cross-linked by RAFT } \\
\text { aqueous dispersion } \\
\text { polymerization }\end{array}$ & $\begin{array}{l}\text { Core-shell nanogel containing linear poly(ethylene } \\
\text { glycol) and/or nonlinear polymer with oligo(ethylene } \\
\text { glycol) side chains (Shen et al. 2011, Fu et al. 2017) }\end{array}$ \\
\hline Multilayer nanogels & $\begin{array}{l}\text { Cross-linked by dispersion } \\
\text { polymerization }\end{array}$ & $\begin{array}{l}\text { Poly(NIPAM-co-AA-co-rhodamine) nanogel with layer- } \\
\text { by-layer assembly of polyelectrolytes (Wong et al. 2009) }\end{array}$ \\
\hline Functionalized nanogels & $\begin{array}{l}\text { Cross-linked by three-step } \\
\text { cross-linking }\end{array}$ & $\begin{array}{l}\text { Diblock copolymer of poly(ethylene oxide)-b- } \\
\text { poly(methacrylic acid) (PEG-b-PMA) with folate } \\
\text { targeting group (Nukolova et al. 2011, Lv et al. } 2018 \text { ) }\end{array}$ \\
\hline
\end{tabular}

Polymerization of monomers in a homogeneous phase or a micro- and/or nano-heterogeneous phase

Polymerization suitable for nanogel formation can be divided into two types, emulsion and inverse emulsion polymerization. In the latter, inverse water in oil nano-emulsion as a medium for the polymerization of monomers is used. Indeed, stable nanogels are obtained after the addition of specific co-monomers, which serve as bifunctional cross-linkers. The Khmelnitsky group (Khmelnitsky et al. 1992) described covalently immobilized enzymes in polymer nanogels based on the copolymerization of acrylamide with $N, N$-methylene-bisacrylamides. Polymerization leading to nanogels may also be carried out in oil in water nano-emulsion or in an 
aqueous suspension. In some cases, the polymerization can be initiated in a homogeneous aqueous solution, which changes during polymerization to a milky suspension containing the growing nanogel. The final product is then separated from suspension by freezedrying. One example is the synthesis of poly(methacrylic acid-grafted-poly(ethylene glycol)) nanogels, which are promising candidates for oral protein delivery, in water by using a combination of UV-initiated free-radical solution/precipitation polymerization. Methacrylic acid, O-(methacryl)-O'-methylpolyethylene glycol with different molecular weights (200, 400 and 1,000) were used as monomers, tetraethylene glycol dimethacrylate was used as a cross-linker and 1-hydroxycyclohexylphenyl ketone was used as UV initiator (Donini et al. 2002).

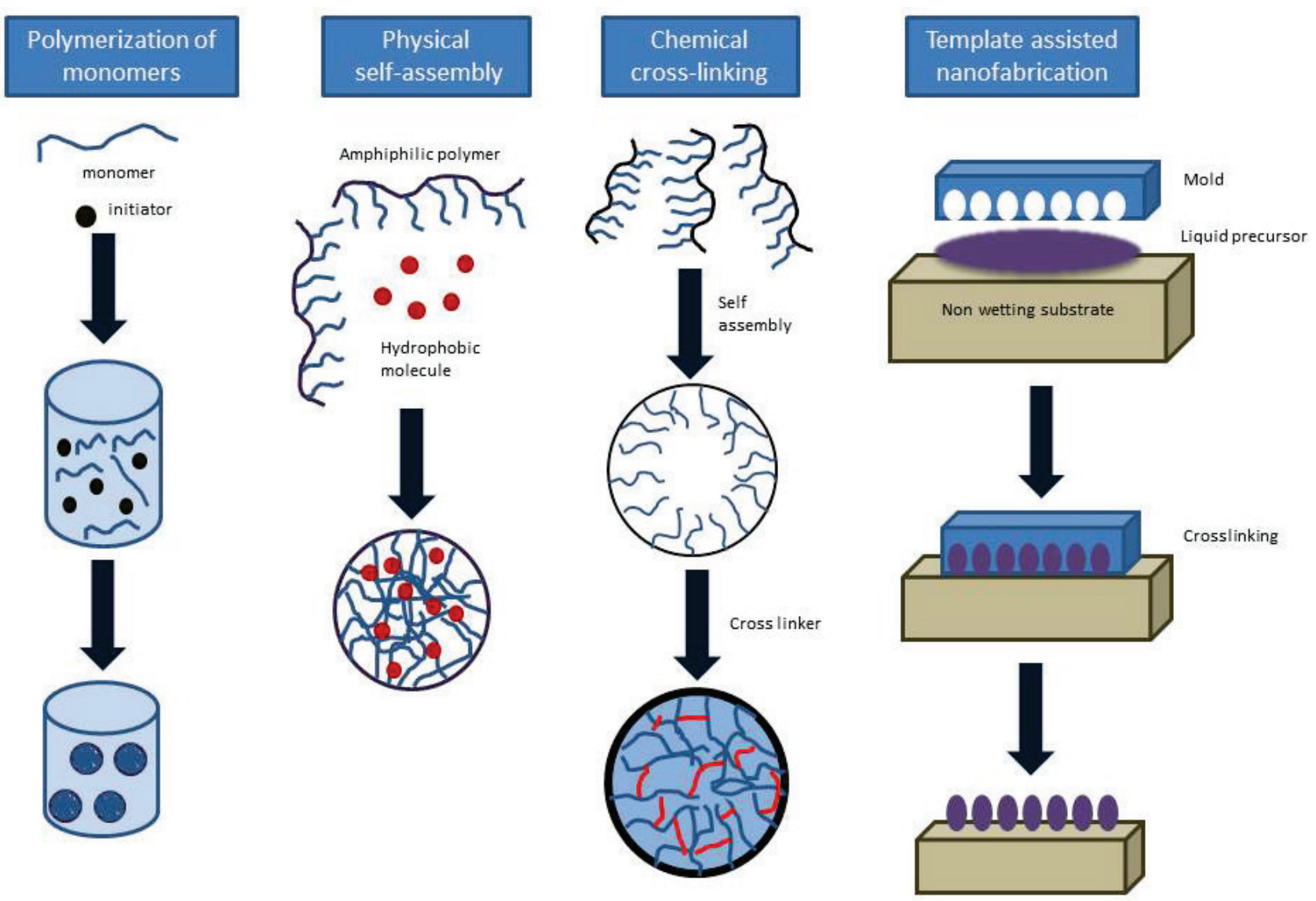

Fig. 2. Schematic representation of different methods for the preparation of nanogels.

\section{Cross-linking of polymers}

Another variant of nanogel synthesis is the cross-linking of polymer chains to form covalent bonds (Hennink and van Nostrum 2012). The cross-linking method has been successfully used for the synthesis of various functionalized nanogels for the transport of drugs. For example, this procedure was used to synthesize the first cross-linked cationic nanogel for the transport of polynucleotides (Vinogradov et al. 1999). In this case, double-activated PEG was conjugated to branched PEI in an oil/water emulsion.

- Disulphide-based cross-linking

The disulphide bond is stimuli sensitive and biodegradable by biochemical reductants such as glutathione or thioredoxin I/II. As an example, we can mention nanogels prepared by the cross-linking of polymers containing polyethylene glycol as a hydrophilic unit and pyridyldisulphide as a cross-linkable unit. The addition of catalytic amounts of dithiothreitol reduced a controlled amount of pyridyldisulphide group to thiols located in the polymer matrix, which further exchanged with remaining pyridyldisulphide groups, yielding a cross-linked nanogel. The size of particles can be controlled in this particular case by the amount of dithiothreitol. This system was used for the controlled delivery of doxorubicin (Li et al. 2009, Jiwpanich et al. 2010, Chacko et al. 2012). 
- Amino groups involved in cross-linking

A great advantage of using diamines as a crosslinker is their good reactivity with activated esters, isothiocyanides, activated amides or carboxylic acids in the presence of coupling agents. In addition to other nanogels, synthesis of shell cross-linked structures using a diamine cross-linker was developed by (Huang et al. 1998). A variety of amphiphilic block copolymers, which contain poly(acrylic acid), were used as the cross-linkable part. For example, polystyrene- $b$-poly(acrylic acid) as an amphiphilic polymer was used for the synthesis of coreshell nanogels. Poly(ethylene glycol)diamine was used as a suitable cross-linker (Huang et al. 1998, Joralemon et al. 2005, Li et al. 2008, Chacko et al. 2012).

- Cross-linking using click chemistry

Click chemistry can be used to synthesize nanogels at high yield either by catalyzed or non-catalyzed click reaction. As an interesting example of a core-shell nanogel, we can mention the system based on assembled nanoparticles prepared from amphiphilic diblock copolymer of poly(acrylic acid)-b-poly(styrene) in which acrylic acid was coupled with propargylamine using 1-ethyl-3-(3-dimethylaminopropyl)carbodiimide as a coupling agent. In the following reaction the triple bonds of the propargylamine group react with a suitable azido-containing cross-linker to form a cross-linked shell of the core-shell nanogel (Joralemon et al. 2005).

\section{Template-assisted nanofabrication}

DeSimone developed (Gratton et al. 2007) this new imprinting method, also known as particle replication in non-wettable templates (PRINT), which is suitable for the production of nanogels. Polymeric nanoparticles in the range of tens of nanometers to several micrometers can be prepared using this method. This method allows particle size control, composition, shape, surface functionality and good loading control of pharmaceuticals and biomacromolecules. For example, PEG-based monodispersed swelling particles have been prepared using this method by UV-induced copolymerization of several monomers, such as trimethylolpropane ethoxylate triacrylate, O-(methacryl)-O'methylpolyethylene glycol and $p$-hydroxystyrene. The master template is created using lithographic techniques. Liquid fluoropolymer is added to the surface of this template. While this fluoropolymer is wetting the template, it is photochemically cross-linked. A form with nanoscale cavities is generated. Due to the low surface energy and high gas permeability, the organic liquid precursor could fill the cavities through capillary action. Indeed, an inter-connecting layer of liquid wetting the area between the cavities is not formed. Nanoparticles prepared using this method have the same precise shape of the master template they were derived from (Rolland et al. 2005, Gratton et al. 2007, Napier and DeSimone 2007).

\section{Characterization of nanogels}

Prior to use, nanogels should be well characterized and the following methods are generally considered suitable for this purpose issue:

\section{Dynamic light scattering}

Dynamic light scattering (DLS) is a technique used to determine the size distribution profile of nanoparticles in solutions. During the measurements, light scattering is recorded in a microsecond time scale. The effective hydrodynamic particle radius can be used to measure the effect of the cross-linker and the possible charge of the polymer chains on the size of the formed nanogel. DLS can also be used to measure the swelling of nanogels in different media (McAllister et al. 2002, Chen et al. 2007). It is worth mentioning that the DLS data should not be overestimated as the DLS measurements in neglecting population of the smaller polymer particles. A combination of analytical methods is often needed to fully understand the characteristics of nanogels.

\section{Scanning electron microscopy}

An electron microscopy provides the ability to determine the particle surface as well as its size. Scanning electron microscopy (SEM) can be used to measure particle size from $50-80 \mathrm{~nm}$ and to determine the morphological characteristics of nanogels (Somasundaran and Chakraborty 2004).

\section{Circular dichroism}

Circular dichroism (CD) serves to detect the optical activity of the resulting product. This method is particularly suitable for detecting chiral molecules that have been inserted into nanogels. Their presence leads to macromolecular structures with a chiral center based on spiral structures that can be detected by $\mathrm{CD}$ (Somasundaran and Chakraborty 2004).

\section{Size-exclusion chromatography}

Size-exclusion chromatography (SEC) is a method that divides the material according to its size. It is most commonly used to measure the distribution of the nanogel molar mass and the molar mass of individual fractions (Shidhaye et al. 2008). 


\section{Field-flow fractionation}

Field-flow fractionation (FFF) is a separation techniques in which cross-flow is applied to a solution or suspension which is pumped through a long narrow channel. The direction of this cross-flow is perpendicular to the direction of flow. Since FFF can separate polymer material over a wide colloidal size range while maintaining high resolution, it is a unique method in comparison to other separation techniques. Generally, FFF is based on the laminar flow of particles in a solution. Sample components flow at various velocities due to their size/mass and thus separation occurs due to different speed of the components (Giddings et al. 1976).

\section{Nanoparticle tracking analysis}

Nanoparticle tracking analysis (NTA) is a technique for sizing particles from approximately 30 to $1,000 \mathrm{~nm}$. This technique combines laser light scattering microscopy with a charge-coupled device camera that enables the visualization and recording of nanoparticles in a solution. NTA is able to identify and track individual nanoparticles moving under Brownian motion and relates the movement to particle size. Both particular size and concentration are measured (Gyawali et al. 2017).

\section{Swelling studies of nanogels}

Swelling is the most important property of nanogels and is characterized by measuring their capacity to absorb water or an aqueous solution. The easiest way to determine the kinetics and swelling equilibrium is to measure weight, with the degree of swelling being calculated from the weight portion of the swollen nanogel and the initial weight. The swelling of the nanogel is influenced by the following factors: type and composition of the monomer, cross-link density, $\mathrm{pH}$, temperature and ionic strength (Kopeček 2002, Vinogradov et al. 2005).

\section{Nanogels as drug carriers}

Nanogels are suitable for the delivery of various drugs from hydrophobic to hydrophilic ones. There are several methods described in the literature for the encapsulation or attachment of drugs. The following section describes the commonly used approaches:

\section{Covalent conjugation}

This method leads to the formation of a covalent bond between suitable groups of the drug and the functional groups of the nanogel. The most widely used covalent bonds are stimuli-sensitive, thus enabling the release of the drug at the place of interest within the body. A pH-responsive hydrazone bond between doxorubicin and the methacrylamide polymeric nanogel was used recently for solid tumor drug delivery and activation (Chen et al. 2017). Furthermore, biomacromolecules can be also covalently bound to nanogels. For example, enzymes are attached through a two-step reaction. The first step is the reaction of the enzyme with $\mathrm{N}$-hydroxysuccinimidoacrylate under mild conditions. This reaction generates double bonds on the enzyme surface. The second step is in situ polymerization with acrylamide as the monomer, $N, N^{\prime}$-methylenebisacrylamide as the cross-linker and $N, N, N$ ', $N$ '-tetramethylethylenediamine/ammonium persulfate as the initiator (Yan et al. 2006). Alternatively, polyacrylamide nanogels with incorporated modified $\alpha$-chymotrypsin can be prepared by copolymerization in an inverse micropolymerization reaction (Khmelnitsky et al. 1992). Nanogels containing covalently-bound proteins can increase their thermostability and plasma half-life.

\section{Direct addition method}

In this method, the drug is dissolved together with the monomer in the aqueous phase of the emulsion before the synthesis of the nanogel. The drug is therefore encapsulated in the nanogel structure during its formation by hydrophobic or electrostatic interaction. Using this procedure, aspirin-containing nanogels were prepared by photoisomerization using a solution of the aspirin salt dispersed in a solution of linear dextran containing $N$-(6aminohexyl)-4-[4-hydroxyphenylazo]-benzamide substituent attached via an amide bond. The first step of the synthesis was the preparation of the hydrophobic substituent, while the second step was the reaction of the substituent with dextran. The nanogel was then formed through non-covalent self-aggregation induced by photoisomerization (Patnaik et al. 2007).

\section{Soaking method}

This method is useful in the case of amphiphilic nanogels containing hydrophobic moieties such as cholesterol. The drug can be introduced by simply dipping the nanogels in a supersaturated solution of the drug. For example, this method was used to synthesize indomethacin-carrying nanogels (Sahiner et al. 2007).

\section{Passive and active targeting}

Passive targeting using nanogels in neoplastic disease treatment is, as in the case of other nanomedicines, based on an enhanced permeation retention effect (EPR effect). The vessels nourishing the 
tumor are poorly formed, leading to large gaps and thus increased permeation by macromolecular delivery systems in the range $20-200 \mathrm{~nm}$ occurs. On the other hand, lymphatic drainage is poor due to the rapid growth of the tumor, which leads to nanoparticles remaining in the tumor tissue. Thus, the EPR effect enables the solid tumor tissue to be targeted using size-controlled nanogels. In this regard, tailor-made nanogels with controlled size should present significant advantages for therapies targeting solid tumors and metastases. Moreover, the size of the nanosystem determines the internalization route and speed (Chacko et al. 2012, Rigogliuso et al. 2012).

To obtain active targeting, nanogels have to be functionalized with suitable molecules that are capable of recognizing and binding to specific receptors on the targeted cells. These receptors should be primarily expressed on the targeted cells. Generally, large macromolecules (e.g. monoclonal antibodies) or small molecules (e.g. oligopeptides or oligosaccharides) may be used as targeting ligands to the receptors on the targeted cells. The significance of this strategy can be demonstrated, for example, in DNA drug delivery systems in which the sequence of the cell-penetrating peptide leads to significant differences in DNA delivery efficiency (Roy et al. 2009). This work demonstrated the importance of post-assembly surface modification of the drug-loaded delivery system. If the TAT peptide was attached to the preformed assembly, delivery transfection efficiency was about $25 \%$ higher than when the TAT peptide was attached to the delivery system before complexing with DNA (Chacko et al. 2012). Encapsulated paclitaxel in nanogels was actively targeted to liver, breast or prostate tumors using galactosamine, transferrin, anti-HER2 or fragments of mAbs (anti-HER2 scFv F5) as moieties selective for those cancer cells (Park et al. 2001, Sahoo et al. 2004, Xu et al. 2005, Liang et al. 2006, Steinhauser et al. 2006, Sun et al. 2008).

\section{Application}

\section{Nanogels in cancer therapy}

Many drug delivery systems, mainly nanoparticles, liposomes and soluble polymer systems, have been investigated to overcome the limitation of standard chemotherapeutics such as narrow therapeutic window, poor solubility and cytotoxicity to normal tissues (Zhang et al. 2016). Nanogels were used in the treatment of cancer and as carriers of the following low-molecular weight drugs: doxorubicin, cisplatin, 5-fluorouracil, temozolomide, andriamycin, neocarzinostatin etc. (Morimoto et al. 2006, Shidhaye et al. 2008, Sharma et al. 2016). Nanogels containing doxorubicin are often studied in the treatment of cancer in the form of $\mathrm{pH}$ - and temperature-responsive nanogels based on maleic acid poly-( $N$-isopropylacrylamide) polymers. Doxorubicin is released from these nanogels following a slight decrease in $\mathrm{pH}$ or through temperature stimulus (Sharma et al. 2016). In addition, a chitin-based doxorubicin-bearing nanogel was studied in the treatment of prostate, breast, lung and liver cancer. Table 2 summarizes the different types of nanogels used to treat cancer.

\section{Nanogels for delivery of protein and peptide}

Nanogels can also be used as carriers of proteins and peptides to the target site. Artificial nanogels are one of the possible carriers used to transport various proteins (Sharma et al. 2016). Different types of nanogels used in the controlled delivery of protein and peptides are listed in the Table 3.

\section{Nanogels for gene and antisense delivery}

Progress in recent years in the field of gene and antisense therapy has led to the implementation of safe, effective drug delivery systems. Various viral and non-viral vectors have been tested for the delivery of oligonucleotides. However, due to the limitations of viral vectors (immune response and toxicity), significant emphasis has also been given to non-viral vectors. Taking into account the limiting factors of classical non-viral vectors, namely correct size achievement and poor stability, a huge effort was made to develop polymeric nanogels of a size less than $200 \mathrm{~nm}$ that were able to form monodisperse complexes with DNA or oligonucleotides. The nanogel-oligonucleotide complex was shown to increase the physico-chemical stability of the oligonucleotide and to enable targeted delivery of the oligonucleotide (Shidhaye et al. 2008). McAllister et al. reported the synthesis of monodisperse and non-toxic cationic nanogels capable of forming stable complexes with oligonucleotides. The system was prepared through the inverse microemulsion polymerization of 2-acryloxyethyltrimethylammonium chloride with 2-hydroxyethylacrylate and poly(ethylene glycol)diacrylate. The quaternary ammonium group of the 2-acryloxyethyltrimethylammonium chloride-based monomeric unit promoted $\mathrm{pH}$-independent condensation of the oligonucleotide via electrostatic dissociation between the phosphate group of the oligonucleotide and the quaternary ammonium group (McAllister et al. 2002). 
Table 2. List of nanogels investigated in cancer treatment

\begin{tabular}{|c|c|c|c|c|}
\hline Nanogel constitution & Type of nanogel & Drug used & Applications & References \\
\hline $\begin{array}{l}\text { Poly(N-isopropylacrylamide-co- } \\
\text { metacrylic acid-co- } N, N \text { '- } \\
\text { methylenbisacrylamide-co-O- } \\
\text { (methacryl)-O'-methylpolyethylene } \\
\text { glycol) }\end{array}$ & $\begin{array}{l}\text { Temperature- and } \\
\text { pH-responsive } \\
\text { nanogel }\end{array}$ & Cisplatin & $\begin{array}{l}\text { Breast cancer } \\
\text { therapy }\end{array}$ & $\begin{array}{l}\text { Peng et al. } \\
\quad 2013\end{array}$ \\
\hline $\begin{array}{l}\text { Poly( } N \text {-isopropylacrylamide-co- } \\
\text { polyethylenimine-co- } N, N \text { '- } \\
\text { methylenebisacrylamide) }\end{array}$ & $\begin{array}{l}\text { Temperature- and } \\
\text { pH- responsive } \\
\text { nanogel }\end{array}$ & 5-fluorouracil & $\begin{array}{l}\text { Mastocarcinoma } \\
\text { therapy }\end{array}$ & $\begin{array}{l}\text { Zhu et al. } \\
2017\end{array}$ \\
\hline Acetylated chondroitin sulphate & $\begin{array}{l}\text { Self-assembled by } \\
\text { hydrophobic } \\
\text { interaction }\end{array}$ & Doxorubicin & Cervical cancer & $\begin{array}{l}\text { Park et al. } \\
\quad 2010\end{array}$ \\
\hline $\begin{array}{l}\text { Poly (acrylic acid-co-N,N'- } \\
\text { methylenebisacrylamide) filled with } \\
\text { hydroxypropylcellulose }\end{array}$ & $\begin{array}{l}\text { Temperature- and } \\
\text { pH-responsive } \\
\text { nanogel }\end{array}$ & Temozolomidine & Melanoma & $\begin{array}{l}\text { Wu et al. } \\
2010\end{array}$ \\
\hline $\begin{array}{l}\text { Poly( } N \text {-isopropylacrylamide-co- } \\
\text { butylacrylate-co- } N, N \text { '- } \\
\text { methylenebisacrylamide) }\end{array}$ & $\mathrm{pH}$-responsive & Methotrexate & $\begin{array}{l}\text { Breast cancer, } \\
\text { lung cancer, } \\
\text { leukemia and } \\
\text { lymphoma }\end{array}$ & $\begin{array}{c}\text { Singka et al. } \\
2010\end{array}$ \\
\hline $\begin{array}{l}\text { Disulphide cross-linked heparin } \\
\text { nanogel }\end{array}$ & Reducible nanogel & Heparin & $\begin{array}{l}\text { Induction of } \\
\text { apoptosis of } \\
\text { melanoma cells }\end{array}$ & $\begin{array}{l}\text { Bae et al. } \\
2008\end{array}$ \\
\hline $\begin{array}{l}\text { Self-assembly pullulan-based } \\
\text { nanogel with folic substituents }\end{array}$ & $\mathrm{pH}$-responsive & Doxorubicin & Cervical cancer & $\begin{array}{l}\text { Kim et al. } \\
2008\end{array}$ \\
\hline
\end{tabular}

Table 3. List of nanogels investigated for protein and peptide delivery.

\begin{tabular}{|c|c|c|c|}
\hline Nanogel constitution & Type of nanogel & Applications & References \\
\hline $\begin{array}{l}\text { Self-assembled cholesterol- } \\
\text { bearing glycogen filled with } \\
\text { cyclodextrin }\end{array}$ & $\begin{array}{l}\text { Nanogel with } \\
\text { thermally stable } \\
\text { properties suitable } \\
\text { for preservation of } \\
\text { proteins }\end{array}$ & $\begin{array}{l}\text { Thermal stabilization of enzyme } \\
\text { for biomedical use, } \\
\text { pharmaceutical and cosmetic } \\
\text { application }\end{array}$ & Takahashi et al. 2011 \\
\hline $\begin{array}{l}\text { Poly(methylacrylic acid-co- } \\
N, N^{\prime} \text {-ethylenebisacrylamide)- } \\
\text { coated } \mathrm{Fe}_{3} \mathrm{O}_{4} \text { nanoparticles }\end{array}$ & $\begin{array}{l}\mathrm{pH}-\text { and } \\
\text { temperature- } \\
\text { responsive }\end{array}$ & $\begin{array}{l}\text { Controlled delivery of } \\
\alpha \text {-chymotrypsine using } \\
\text { a magnetic field }\end{array}$ & Hong et al. 2008 \\
\hline $\begin{array}{l}\text { Self-assembled cholesterol- } \\
\text { bearing pullulan }\end{array}$ & $\begin{array}{l}\text { Stimuli sensitive } \\
\text { (heat, light) }\end{array}$ & $\begin{array}{l}\text { Controlled delivery of bone } \\
\text { anabolic agents, e.g. recombinant } \\
\text { hormones, and cytokines }\end{array}$ & Nomura et al. 2003 \\
\hline
\end{tabular}




\section{Nanogels as vaccine delivery systems}

The induction of a specific immune response against cancer cells is a highly achievable goal in the immune therapy for cancer. Complex vaccines of hydrophobic polysaccharide nanogels containing truncated oncoprotein complexes can induce strong cellular and humoral immune responses against HER2-expressing cancers. Following exposure to the cholesterol-bearing pullulan-HER2 nanogel complex, dendritic cells such as bone marrow-derived APC were capable of eliciting a host immune response through stimulation of the proliferation of $\mathrm{CD}^{+} \mathrm{T}$ cells and $\mathrm{CD} 8^{+}$ T cells (Morimoto et al. 2006).

\section{Nanogels for therapy of Alzheimer's disease}

The formation of fibrils by amyloid $\beta$-protein is considered a key step in the pathology of Alzheimer's disease. Inhibiting the aggregation of amyloid $\beta$-protein represents a promising approach for therapy. Nanogels composed of a polysaccharide pullulan backbone with cholesterol hydrophobic moieties (cholesterol-bearing pullulan) as an artificial absorber of amyloid proteins can be used to inhibit the formation of amyloid $\beta$-protein-(142) fibrils with marked anti-amyloidogenic activity. 6-8 molecules of amyloid $\beta$-protein-(1-42) can be incorporated per one. Nanogels composed of aminogroup modified cholesterol-bearing pullulan with positive charges under physiological conditions showed a superior inhibitory effect than unmodified cholesterol-bearing pullulan possibly due to electrostatic interactions between the amino-group modified nanogel and the amyloid $\beta$-protein, which can be important in the inhibition of fibril formation. In addition, these nanogels can protect PY12 cells from amyloid $\beta$-protein toxicity (Kudva et al. 1997, Ikeda et al. 2006).

\section{Conclusions}

Several synthetic approaches and drug molecule entrapment approaches for the advanced synthesis of nanogel-based drug carriers have been described to review the relationship between the structure and physico-chemical and biological characteristics of nanogel systems. Indeed, the application of these systems as nanomedicines, especially for therapy of neoplastic diseases and other diseases, has been described in detail, showing the potential of these nanogel systems. Taking the recent development of nanogels in consideration, we believe that there is huge potential in future research and clinical evaluation of tailored nanogels with smart properties based on the controlled physico-chemical properties of system, tailor-made degradation and advanced functionalities. We can unequivocally conclude that nanogels are highly interesting polymer carriers suitable for further preclinical development.

\section{Conflict of Interest}

There is no conflict of interest.

\section{Acknowledgements}

The work was supported by the Ministry of Education, Youth and Sports of CR within the National Sustainability Program I, Project LO1507 POLYMAT.

\section{References}

AKIYOSHI K, KOBAYASHI S, SHICHIBE S, MIX D, BAUDYS M, KIM SW, SUNAMOTO J: Self-assembled hydrogel nanoparticle of cholesterol-bearing pullulan as a carrier of protein drugs: complexation and stabilization of insulin. J Control Release 54: 313-320, 1998.

BAE KH, MOK H, PARK TG: Synthesis, characterization, and intracellular delivery of reducible heparin nanogels for apoptotic cell death. Biomaterials 29: 3376-3383, 2008.

BAE Y, JANG W-D, NISHIYAMA N, FUKUSHIMA S, KATAOKA K: Multifunctional polymeric micelles with folate-mediated cancer cell targeting and $\mathrm{pH}$-triggered drug releasing properties for active intracellular drug delivery. Mol Biosyst 1: 242, 2005.

BAL T, ORAN DC, SASAKI Y, AKIYOSHI K, KIZILEL S: Sequential coating of insulin secreting beta cells within multilayers of polysaccharide nanogels. Macromol Biosci 18: 1-12, 2018.

BENCHERIF SA, SIEGWART DJ, SRINIVASAN A, HORKAY F, HOLLINGER JO, WASHBURN NR, MATYJASZEWSKI K: Biomaterials Nanostructured hybrid hydrogels prepared by a combination of atom transfer radical polymerization and free radical polymerization. Biomaterials 30: 5270-5278, 2009. 
CHACKO RT, VENTURA J, ZHUANG J, THAYUMANAVAN S: Polymer nanogels: A versatile nanoscopic drug delivery platform. Adv Drug Deliv Rev 64: 836-851, 2012.

CHEN Y, TEZCAN O, LI D, BEZTSINNA N, LOU B, ETRYCH T, ULBRICH K, METSELAAR JM, LAMMERS T, HENNINK WE: Overcoming multidrug resistance using folate receptor-targeted and $\mathrm{pH}$-responsive polymeric nanogels containing covalently entrapped doxorubicin. Nanoscale 9: 10404-10419, 2017.

CHEN Z, HUA Z, WANG J, GUAN Y, ZHAO M, LI Y: Molecularly imprinted soluble nanogels as a peroxidase-like catalyst in the oxidation reaction of homovanillic acid under aqueous conditions. Appl Catal A Gen 328: 252-258, 2007.

DAOUD-MAHAMMED S, COUVREUR P, GREF R: Novel self-assembling nanogels: stability and lyophilisation studies. Int J Pharm 332: 185-191, 2007.

DONINI C, ROBINSON DN, COLOMBO P, GIORDANO F, PEPPAS NA: Preparation of poly(methacrylic acid-gpoly(ethylene glycol)) nanospheres from methacrylic monomers for pharmaceutical applications. Int $J$ Pharm 245: 83-91, 2002.

FU W, LUO C, MORIN EA, HE W, LI Z, ZHAO B: UCST-Type thermosensitive hairy nanogels synthesized by RAFT polymerization-induced self-assembly. ACS Macro Lett 6: 127-133, 2017.

FUJIOKA-KOBAYASHI M, OTA MS, SHIMODA A, NAKAHAMA KI, AKIYOSHI K, MIYAMOTO Y, ISEKI S: Cholesteryl group- and acryloyl group-bearing pullulan nanogel to deliver BMP2 and FGF18 for bone tissue engineering. Biomaterials 33: 7613-7620, 2012.

GARG T, SINGH O, ARORA S, MURTHY RSR: Scaffold: A novel carrier for cell and drug delivery. Crit Rev Ther Drug Carrier Syst 29: 1-63, 2012.

GIDDINGS CJ, YANG FJ, MYERS MN: Flow-field-flow fractionation: a versatile new separation method. Science 193: 1244-1245, 1976.

GRATTON SEA, POHLHAUS PD, LEE J, GUO J, CHO MJ, DESIMONE JM: Nanofabricated particles for engineered drug therapies: A preliminary biodistribution study of PRINT ${ }^{\mathrm{TM}}$ nanoparticles. $J$ Control Release 121: 10-18, 2007.

GYAWALI D, KIM JP, YANG J: Highly photostable nanogels for fluorescence-based theranostics. Bioact Mater 3: 39-47, 2017.

HAMIDI M, AZADI A, RAFIEI P: Hydrogel nanoparticles in drug delivery. Adv Drug Deliv Rev 60: 1638-1649, 2008.

HAYASHI H, IIJIMA M, KATAOKA K, NAGASAKI Y: pH-sensitive nanogel possessing reactive PEG tethered chains on the surface. Macromolecules 37: 5389-5396, 2004.

HENNINK WE, VAN NOSTRUM CF: Novel crosslinking methods to design hydrogels. Adv Drug Deliv Rev 54: 13-36, 2002.

HONG J, XU D, GONG P, YU J, MA H, YAO S: Covalent-bonded immobilization of enzyme on hydrophilic polymer covering magnetic nanogels. Micropor Mesopor Mater 109: 470-477, 2008.

HUANG H, WOOLEY KL, HUANG H, REMSEN EE: Amphiphilic core-shell nanospheres obtained by intramicellar shell crosslinking of polymer micelles with poly(ethylene oxide) linkers. Chem Commun 13: 1415-1416, 1998.

IKEDA K, OKADA T, SAWADA S, AKIYOSHI K, MATSUZAKI K: Inhibition of the formation of amyloid $\beta$-protein fibrils using biocompatible nanogels as artificial chaperones. FEBS Lett 580: 6587-6595, 2006.

INOMOTO N, OSAKA N, SUZUKI T, HASEGAWA U, OZAWA Y, ENDO H, AKIYOSHI K, SHIBAYAMA M: Interaction of nanogel with cyclodextrin or protein: Study by dynamic light scattering and small-angle neutron scattering. Polymer (Guildf) 50: 541-546, 2009.

JIWPANICH S, RYU JH, BICKERTON S, THAYUMANAVAN S: Noncovalent encapsulation stabilities in supramolecular nanoassemblies. $J$ Am Chem Soc 132: 10683-10685, 2010.

JORALEMON MJ, O'REILLY RK, HAWKER CJ, WOOLEY KL: Shell Click-crosslinked (SCC) nanoparticles: a new methodology for synthesis and orthogonal functionalization. J Am Chem Soc 127: 16892-16899, 2005.

KABANOV AV, VINOGRADOV SV: Nanogels as pharmaceutical carriers: finite networks of infinite capabilities. Angew Chem Int Ed Engl 48: 5418-5429, 2009.

KHMELNITSKY YL, NEVEROVA IN, GEDROVICH AV, POLYAKOV VA, LEVASHOV AV, MARTINEK K: Catalysis by $\alpha$-chymotrypsin entrapped into surface-modified polymeric nanogranules in organic solvent. Eur J Biochem 210: 751-757, 1992. 
KIM S, PARK KM, KO JY, KWON IC, CHO HG, KANG D, YU IT, KIM K, NA K: Minimalism in fabrication of self-organized nanogels holding both anti-cancer drug and targeting moiety. Colloids Surf B Biointerfaces 63 : 55-63, 2008.

KOPEČEK J: Polymer chemistry: swell gels. Nature 417: 388-391, 2002.

KUDVA YC, HIDDINGA HJ, BUTLER PC, MUESKE CS, EBERHARDT NL: Small heat shock proteins inhibit in vitro Aß1-42 amyloidogenesis. FEBS Lett 416: 117-121, 1997.

LEE H, MOK H, LEE S, OH YK, PARK TG: Target-specific intracellular delivery of siRNA using degradable hyaluronic acid nanogels. J Control Release 119: 245-252, 2007.

LI X, LI X, LU X: Synthesis and characterization of multifunctional interpenetrating polymer and its applications in protein adsorption and magnetite loading. Chem Select 2: 5895-5904, 2017.

LI Y, DU W, SUN G, WOOLEY KL: pH-responsive shell cross-linked nanoparticles with hydrolytically labile crosslinks. Macromolecules 41: 6605-6607, 2008.

LI YL, ZHU L, LIU Z, CHENG R, MENG F, CUI JH, JI SJ, ZHONG Z: Reversibly stabilized multifunctional dextran nanoparticles efficiently deliver doxorubicin into the nuclei of cancer cells. Angew Chem Int Ed Engl 48: 9914-9918, 2009.

LIANG HF, CHEN CT, CHEN SC, KULKARNI AR, CHIU YL, CHEN MC, SUNG HW: Paclitaxel-loaded poly( $\gamma$ glutamic acid)-poly(lactide) nanoparticles as a targeted drug delivery system for the treatment of liver cancer. Biomaterials 27: 2051-2059, 2006.

LV Y, YANG B, LI YM, HE F, ZHUO RX: Folate-conjugated amphiphilic block copolymer micelle for targeted and redox-responsive delivery of doxorubicin. J Biomater Sci Polym Ed 29: 92-106, 2018.

MCALLISTER K, SAZANI P, ADAM M, CHO MJ, RUBINSTEIN M, SAMULSKI RJ, DESIMONE JM: Polymeric nanogels produced via inverse microemulsion polymerization as potential gene and antisense delivery agents. J Am Chem Soc 124: 15198-15207, 2002.

MORIMOTO N, NOMURA SM, MIYAZAWA N, AKIYOSHI K: Nanogel engineered designs for polymeric drug delivery. In: ACS Symposium Series, Vol. 924 - Polymeric Drug Delivery II. SVENSON S. (ed), American Chemical Society, Washington, 2006, pp 88-101.

MORIMOTO N, HIRANO S, TAKAHASHI H, LOETHEN S, THOMPSON DH, AKIYOSHI K: Self-assembled pH-sensitive cholesteryl pullulan nanogel as a protein delivery vehicle. Biomacromolecules 14: 56-63, 2013.

NAN J, CHEN Y, LI R, WANG J, LIU M, WANG C, CHU F: Polymeric hydrogel nanocapsules: a thermo and pH dual-responsive carrier for sustained drug release. Nano-Micro Lett 6: 200-208, 2014.

NAPIER ME, DESIMONE JM: Nanoparticle drug delivery platform. Polym Rev 47: 321-327, 2007.

NOMURA Y, IKEDA M, YAMAGUCHI N, AOYAMA Y, AKIYOSHI K: Protein refolding assisted by selfassembled nanogels as novel artificial molecular chaperone. FEBS Lett 553: 271-276, 2003.

NUKOLOVA NV, OBEROI HS, COHEN SM, KABANOV AV, BRONICH TK: Biomaterials Folate-decorated nanogels for targeted therapy of ovarian cancer. Biomaterials 32: 5417-5426, 2011.

OH JK, LEE DI, PARK JM: Biopolymer-based microgels/nanogels for drug delivery applications. Prog Polym Sci 34: 1261-1282, 2009.

OH JK, SIEGWART DJ, MATYJASZEWSKI K: Synthesis and biodegradation of nanogels as delivery carriers for carbohydrate drugs. Biomacromolecules 8: 3326-3331, 2007.

PARK JW, KIRPOTIN DB, HONG K, SHALABY R, SHAO Y, NIELSEN UB, MARKS JD, PAPAHADJOPOULOS D, BENZ CC: Tumor targeting using anti-her2 immunoliposomes. J Control Release 74: 95-113, 2001.

PARK W, PARK SJ, NA K: Potential of self-organizing nanogel with acetylated chondroitin sulfate as an anti-cancer drug carrier. Colloids Surf B Biointerfaces 79: 501-508, 2010.

PATNAIK S, SHARMA AK, GARG BS, GANDHI RP, GUPTA KC: Photoregulation of drug release in azo-dextran nanogels. Int J Pharm 342: 184-193, 2007.

PENG J, QI T, LIAO J, CHU B, YANG Q, LI W, QU Y, LUO F, QIAN Z: Controlled release of cisplatin from pH-thermal dual responsive nanogels. Biomaterials 34: 8726-8740, 2013.

RIGOGLIUSO S, SABATINO MA, ADAMO G, GRIMALDI N, DISPENZA C, GHERSI G: Polymeric nanogels: Nanocarriers for drug delivery application. Chem Eng Trans 27: 247-252, 2012. 
ROLLAND JP, MAYNOR BW, EULISS LE, EXNER AE, DENISON GM, DESIMONE JM: Direct fabrication and harvesting of monodisperse, shape-specific nanobiomaterials. J Am Chem Soc 127: 10096-10100, 2005.

ROY R, JERRY DJ, THAYUMANAVAN S: Virus-inspired approach to nonviral gene delivery vehicles. Society 2189-2193, 2009.

SAHINER N, ALB AM, GRAVES R, MANDAL T, MCPHERSON GL, REED WF, JOHN VT: Core-shell nanohydrogel structures as tunable delivery systems. Polymer (Guildf) 48: 704-711, 2007.

SAHOO SK, MA W, LABHASETWAR V: Efficacy of transferrin-conjugated paclitaxel-loaded nanoparticles in a murine model of prostate cancer. Int J Cancer 112: 335-340, 2004.

SHARMA A, GARG T, AMAN A, PANCHAL K, SHARMA R, KUMAR S, MARKANDEYWAR T: Nanogel-an advanced drug delivery tool: Current and future. Artif Cells Nanomed Biotechnol 44: 165-177, 2016.

SHEN W, CHANG Y, LIU G, WANG H, CAO A, AN Z: Biocompatible, antifouling, and thermosensitive core-shell nanogels synthesized by RAFT aqueous dispersion polymerization. Macromolecules 44: 2524-2530, 2011.

SHIDHAYE S, LOTLIKAR V, MALKE S, KADAM V: Nanogel engineered polymeric micelles for drug delivery. Curr Drug ther 3: 209-217, 2008.

SINGKA GSL, SAMAH NA, ZULFAKAR MH, YURDASIPER A, HEARD CM: Enhanced topical delivery and anti-inflammatory activity of methotrexate from an activated nanogel. Eur J Pharm Biopharm 76: 275-281, 2010.

SIVARAM AJ, RAJITHA P, MAYA S, JAYAKUMAR R, SABITHA M: Nanogels for delivery, imaging and therapy. Wiley Interdiscip Rev Nanomed Nanobiotechnol 7: 509-533, 2015.

SOMASUNDARAN S, CHAKRABORTY P: Polymeric nanoparticles and nanogels for extraction and release of compounds. Assignee: Columbia University of New York. Patent App. WO2006052285A2, 2006.

SONI G, YADAV KS: Nanogels as potential nanomedicine carrier for treatment of cancer: A mini review of the state of the art. Saudi Pharm J 24: 133-139, 2016.

STEINHAUSER I, SPÄNKUCH B, STREBHARDT K, LANGER K: Trastuzumab-modified nanoparticles: Optimisation of preparation and uptake in cancer cells. Biomaterials 27: 4975-4983, 2006.

SUN B, RANGANATHAN B, FENG SS: Multifunctional poly(d,l-lactide-co-glycolide)/montmorillonite (PLGA/MMT) nanoparticles decorated by Trastuzumab for targeted chemotherapy of breast cancer. Biomaterials 29: 475-486, 2008.

SUN H, YU J, GONG P, XU D, HONG JUN, ZHANG C, YAO S: Novel core - shell magnetic nanogels synthesized in an emulsion-free aqueous system under uv irradiation for potential targeted radiopharmaceutical applications. Int J Nanosci 5: 253-259, 2006.

TAKAHASHI H, SAWADA S, AKIYOSHI K: Amphiphilic polysaccharide nanoballs : biomedical engineering and artificial. ACS Nano 5: 337-345, 2011.

UTHAMAN S, MAYA S, JAYAKUMAR R, CHO CS, PARK IK: Carbohydrate-based nanogels as drug and gene delivery systems. J Nanosci Nanotechnol 14: 694-704, 2014.

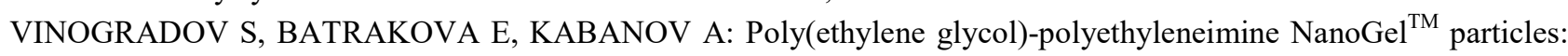
novel drug delivery systems for antisense oligonucleotides. Colloids Surf B Biointerfaces 16: 291-304, 1999.

VINOGRADOV SV, ZEMAN AD, BATRAKOVA EV, KABANOV A: Polyplex Nanogel formulations for drug delivery of cytotoxic nucleoside analogs. J Control Release 107: 143-157, 2005.

VINTILOIU A, LEROUX JC: Organogels and their use in drug delivery - a review. J Control Release 125: 179-192, 2008.

WONG JE, MÜLLER CB, DÍEZ-PASCUAL AM, RICHTERING W: Study of layer-by-layer films on thermoresponsive nanogels using temperature-controlled dual-focus fluorescence correlation spectroscopy. J Phys Chem B 113: 15907-15913, 2009.

WU W, AIELLO M, ZHOU T, BERLINER A, BANERJEE P, ZHOU S: In-situ immobilization of quantum dots in polysaccharide-based nanogels for integration of optical $\mathrm{pH}$-sensing, tumor cell imaging, and drug delivery. Biomaterials 31: 3023-3031, 2010.

XING Z, WANG C, YAN J, ZHANG L, LI L, ZHA L: Dual stimuli responsive hollow nanogels with IPN structure for temperature controlling drug loading and $\mathrm{pH}$ triggering drug release. Soft Matter 7: 7992, 2011. 
XU Z, GU W, HUANG J, SUI H, ZHOU Z, YANG Y, YAN Z, LI Y: In vitro and in vivo evaluation of actively targetable nanoparticles for paclitaxel delivery. Int J Pharm 288: 361-368, 2005.

YAN M, GE J, LIU Z, OUYANG P: Encapsulation of single enzyme in nanogel with enhanced biocatalytic activity and stability. J Am Chem Soc 128: 11008-11009, 2006.

ZAMUROVIC M, CHRISTODOULOU S, VAZAIOS A, IATROU E, PITSIKALIS M, HADJICHRISTIDIS N: Micellization behavior of complex comblike block copolymer architectures. Macromolecules 40: 5835-5849, 2007.

ZHANG H, ZHAI Y, WANG J, ZHAI G: New progress and prospects: The application of nanogel in drug delivery. Mater Sci Eng C 60: 560-568, 2016.

ZHU X, SUN Y, CHEN D, LI J, DONG X, WANG J, CHEN H, WANG Y, ZHANG F, DAI J, PIRRACO RP, GUO S, MARQUES AP, REIS RL, LI W: Mastocarcinoma therapy synergistically promoted by lysosome dependent apoptosis specifically evoked by 5-Fu@nanogel system with passive targeting and pH activatable dual function. J Control Release 254: 107-118, 2017. 